\title{
Venho aqui para existir: um exercício de leitura acerca das relações entre biblioteca pública, sociabilidade, enraizamento e identidade
}

\section{Fabrício José Nascimento da Silveira}

Bibliotecário e professor adjunto da Escola de Ciência da Informação (ECI) da Universidade Federal de Minas Gerais (UFMG) nas modalidades graduação e pós-graduação.

Alcenir Soares dos Reis

Socióloga, doutora em Educação e professora da Escola de Ciência da Informação - ECI/UFMG.

http://dx.doi.org/10.1590/1981-5344/3038

Este trabalho tem por objetivo analisar a participação das bibliotecas públicas no processo de elaboração intersubjetiva de referenciais identitários, tendo como aportes teóricos os conceitos de identidade, enraizamento e sociabilidade. Para tanto, adota-se por premissa que a identidade se dá a ver como um discurso em permanente processo de elaboração, expresso e potencializado através do contato com o outro nas inúmeras esferas de socialização que fomentam a existência de uma coletividade. Dinâmica estimulada, também, pelas bibliotecas públicas, sobretudo em virtude do estatuto representacional que atravessa seus acervos, serviços e setores. Proposições confirmadas por meio da análise das histórias de vida de dois usuários da Biblioteca Pública Estadual Luiz de Bessa. Ao evidenciarem nos depoimentos os distintos pontos de ancoragem que sustentam suas referências interpessoais e a importância da Luiz de Bessa - dimensões simbólicas, afetivas e estruturais - ao longo desse processo formativo, as narrativas erigidas pelos depoentes revelam que a Biblioteca se posta como lugar de enraizamento e marco representativo dos discursos identitários por eles forjados.

Palavras-chave: Biblioteca Pública; Identidade; Enraizamento; Sociabilidade, Histórias de vida; Biblioteca Pública Estadual Luiz de Bessa. 


\section{I come here to be: an exercise of reading about the relationship among public library, sociability, rooting and identity}

The aim of this essay is to discuss the participation of public libraries in the intersubjective development process of identity references. It was tailored as theoretical framework the concepts of identity, rooting and sociability. For such, adopt as a premise that identity is to be seen as a discourse in constant development, expressed and enhanced through the contact with each other in many spheres of socialization that ensure the existence of a collectivity, stimulated dynamic, also by public libraries because of the representational status that crosses their collections and services sectors. The propositions were confirmed by the analysis of the life stories of two users of the library "Biblioteca Pública Estadual Luiz de Bessa". Evidencing in the statements the different anchor points that support their interpersonal references and the importance of Luiz de Bessa - symbolic dimensions, affective and structural - throughout this formative process, the narratives erected by the deponents reveal that the Library exerts a force of impregnating on their individual biographies and put itself as a place of rooting and representational frame of the identity discourses forged by them.

Key Words: Public Library; Identity; Rooting, Sociability, Life Stories, State Public Library Luiz de Bessa.

Recebido em 30.12.2016 Aceito em 22.08.2017

\section{Introdução}

Ao fim de uma palestra proferida em uma biblioteca pública no subúrbio de Paris, Michèle Petit (2013, p.51) relata ter sido abordada por uma mulher de idade já avançada que lhe confidenciou o seguinte testemunho: empregada doméstica, ouvira falar de um café literário que ocorreria naquele espaço e, enquanto usuária assídua da instituição, resolveu participar. Chegando lá, ao se deparar com um público formado basicamente por professores, esteve a ponto de ir embora por supor que a 
conferência abordaria temas elevados demais para ela. Porém, arriscou ficar. Foi então que, ao falar de sua relação com aquele lugar, a senhora proclamou: "venho aqui para existir".

Como podemos explicar uma afirmativa tão contundente? Por que alguém vai a uma biblioteca para poder existir? Entender o relato dessa senhora requer pensar a biblioteca pública e suas especificidades para além daquelas quatro funções que a literatura tradicionalmente aponta como características básicas de tais espaços: função informativa, cultural, recreativa e educacional. É evidente que cada uma delas possui um poder de afetação ${ }^{1}$ sobre as vidas das pessoas que frequentam tais lugares, mas não determinam sua existência. Contribuem para que possam formular representações de si, do mundo e do outro; para ampliarem seus horizontes de expectativas em relação à vida, ao tempo e ao próprio esquecimento; para experimentarem prazeres fortuitos, chegarem à catarse e vislumbrarem o poder poético das palavras, mas não determinam sua existência. Sendo assim, estaria a interlocutora de Michèle Petit equivocada?

Acreditamos que não. Mais que responder às exigências do trabalho mnêmico, que reunir objetos e documentos informacionais para subsidiar as atividades educativas e dar vazão aos desejos de seus leitores, uma biblioteca pública é quase sempre constituída para se tornar um território de cultura, sendo mais preciso, de culturas. Portanto, enquanto instituição pública aberta à confluência de olhares, vozes e manifestações que mimetizam os valores e normas definidores de uma dada paisagem espaço-temporal, tal lugar pode sim ser apreendido como instância onde a vida social subsiste e se revigora. Mas estamos falando aqui de uma forma intersubjetiva de existência, de um olhar particular que por vezes lançamos sobre nós mesmos. Da busca por indícios que nos ajudem a entender quem somos e o que nos tornamos, teria a biblioteca pública como contribuir para tanto?

Este texto objetiva demonstrar que sim. Razão pela qual parte do pressuposto de que ao conjugar em torno de si os estratos físicos e simbólicos representantes de um plano mais amplo da cultura geral, as bibliotecas públicas instauram-se como espaço propício para que seus usuários acessem um conjunto multivariado de referências que podem ajudá-los a construir pontos de interconexão entre sua biografia individual e os fatos, alusões e narrativas instituintes da história e da realidade do grupo ao qual pertencem. Defendemos ainda que seu caráter público se notabiliza mais pela acolhida à diferença e à diversidade das expressões culturais que propriamente por sua ligação com programas de políticas públicas. Isto porque, é a acolhida à diversidade e à diferença que faculta a criação de laços de solidariedade entre os sujeitos e as bibliotecas

\footnotetext{
${ }^{1}$ A expressão poder de afetação refere-se aqui a um processo de descontinuidade instaurada por nosso contato com as bibliotecas públicas e o universo de práticas que atravessam e demarcam tal contato. Trata-se, pois, de uma reação suscitada por algum acontecimento que estimule nossas experiências perceptivas, sendo mais preciso, àquilo que, de acordo com Simões (2012, p.92): "instaura uma descontinuidade na experiência dos sujeitos e movimenta o estado de coisas vigentes, bem como o posicionamento dos sujeitos afetados".
} 
públicas, bem como o reconhecimento de seus atributos e funções enquanto organismo social.

Sendo assim, ao apresentar-se como um lugar aberto à pluralidade humana, elas se afirmam como instâncias que necessitam da presença do outro para se constituírem. Por sua vez, ao reconhecê-las como espaço público, esse outro edifica para si um marco concreto onde pode se mostrar no mundo. Um marco que o ajuda a sair do anonimato e a se revelar no discurso e na ação como alguém que porta uma identidade singular, haja vista que, conforme aponta Hannah Arendt (1991, p.189), "é com palavras e atos que nos inserimos no mundo humano; e esta inserção é como um segundo nascimento, no qual confirmamos e assumimos $o$ fato original e singular do nosso aparecimento físico original".

Ser alguém que porta uma identidade singular, era isso o que aquela senhora queria dizer com o verbo existir. Uma existência que tem nas sensações, experiências e relações vivenciadas no interior de uma biblioteca pública do subúrbio de Paris o seu pólo de ancoragem. Uma ancoragem que advém de suas escolhas enquanto leitora, dos diálogos estabelecidos com os bibliotecários e outros usuários, dos conhecimentos que julga ter "adquirido" em suas dependências, das amizades e encontros que ali se deram, das lembranças enraizadas em torno dos livros que compõem seu acervo, bem como dos desejos, sonhos, anseios e frustrações socializadas em horas de descuido e resignação que escapam à dureza do trabalho doméstico ou às responsabilidades da vida familiar. Indicativos que nos levam a acreditar que as bibliotecas públicas são mesmo territórios onde vamos para existir.

Proposições que se tornarão mais claras a partir do momento em que demonstrarmos a estreita ligação que se estabelece entre as bibliotecas públicas e os processos de constituição dos referenciais identitários de seus leitores e usuários. Para tanto, traçamos um percurso analítico discursivo centrado em duas estratégias distintas, a primeira, alocada no plano teórico, objetiva ampliar a compreensão daquilo que estamos chamando aqui de identidade e como esta se torna melhor apreensível quando aproximamos tal noção dos conceitos de enraizamento e sociabilidade. A segunda, analítica por natureza, propõese a avaliar qual o lugar simbólico e afetivo dispensado à biblioteca pública, em particular à Biblioteca Pública Estadual Luiz de Bessa, nas memórias e histórias de vida de dois de seus usuários, buscando-se assimilar, assim, a presença dessa instituição no discurso que modula uma imagem de si para cada um desses sujeitos. Passemos, pois, às formulações teóricas.

\section{Identidade, enraizamento e sociabilidade: três universos conceituais em interação}

Falar sobre identidade e produção de referenciais identitários no mundo contemporâneo implica adotar por prerrogativa a ideia de que 
talvez a marca mais eminente da conjuntura sócio-histórica atual seja a fragmentação. Isso porque, se até o início do século $X X$ os sujeitos eram "identificados" a partir de enquadramentos políticos, sociais, sexuais, econômicos e culturais estáveis, as mudanças produzidas pela globalização imprimiram novas configurações para as muitas esferas de sociabilidade com as quais se tornou possível interagir. Razão pela qual, segundo Stuart Hall (2001, p.07), as velhas identidades que por tanto tempo estabilizaram a vida social entraram em declínio, fazendo surgir novas identidades e fragmentando o indivíduo moderno, até aqui visto como um sujeito unificado.

Pensada até aquele momento como uma imagem vinculada à ideia de originalidade, de semelhança, de algo que costura e mantém a unidade, o indivíduo globalizado passa a experimentar a identidade como um discurso em permanente processo de elaboração. Agora, ela nos é revelada, de acordo com Bauman (2005, p.21-22), "como algo a ser inventado, e não descoberto; como alvo de um esforço, "um objetivo"; como uma coisa que ainda se precisa construir a partir do zero ou escolher entre alternativas e então lutar por ela e protegê-la lutando ainda mais", ou seja, como uma produção que nunca se completa, formada e transformada no interior das representações. Representações que, por sua vez, se forjam, também, através do prisma da multiplicidade, da urdidura dos diversos discursos e práticas simbólicas que nos posicionam no mundo, que dizem nosso lugar em relação ao outro - outros pontos de referência, outros portos de ancoragem. Com isso, as referências e os marcadores identitários instituídos por nós e para nós passam a serem organizados relacionalmente em um "jogo de posicionamentos, de deslocamentos entre sujeitos que vivem num mundo, falam num mundo e, nesse falar, se reposicionam continuamente" (FRANÇA, 2002, p.38).

Mudança de percepção que vincula nossas representações identitárias à idéia de projeto, de algo que se encontra sempre em construção. Com isso, a crença de que a identidade seria formada por associação a códigos simbólicos supostamente estáveis, homogêneos, coesos e unificados também se dissolve. É o que sugere mais uma vez Bauman ao observar que, no momento histórico atual:

Tornamo-nos conscientes de que o "pertencimento" e a "identidade" não têm a solidez de uma rocha, não são garantidos por toda vida, são bastante negociáveis e revogáveis, e de que as decisões que o próprio indivíduo toma, os caminhos que percorre, a maneira como age - a determinação de se manter firme a tudo isso - são fatores cruciais tanto para o "pertencimento" quanto para a "identidade" (BAUMAN, 2005, p.17).

Portanto, enquanto elaborações estruturadas discursiva e relacionalmente, nossos enquadramentos identitários não se manifestam tendo como única referência a identificação das semelhanças, visto instituírem, nesse mesmo movimento, a construção da diferença e da distinção. Sendo assim, tentar idealizar um discurso representacional para si e para o outro que seja único, coeso e completo em si mesmo torna-se, 
na atual conjuntura histórica, uma fantasia, uma vez que nos tornamos capazes de assumir, através de nossos posicionamentos, falas e ações, identidades múltiplas nos diversos momentos e espaços aonde nossa vida e nossas práticas de atuação sobre 0 mundo adquirem sentido e encontram ressonâncias.

É em função de tais aspectos que a identidade deve ser apreendida como uma construção que se vincula, também, às práticas sociais e ao olhar do outro. Se a linguagem fornece ao indivíduo sistemas de classificação, é na inter-relação entre os sujeitos de uma sociedade que o sentido irá se constituir. Razão pela qual se faz necessário esclarecer, já neste momento, que:

O conceito de identidade aqui desenvolvido não é, portanto, um conceito essencialista, mas um conceito estratégico e posicional. Isto é, de forma diretamente contrária àquilo que parece ser sua carreira semântica oficial, esta concepção de identidade não assinala aquele núcleo estável do eu que passa, do início ao fim, sem qualquer mudança, por todas as vicissitudes da história. Esta concepção não tem como referência aquele segmento do eu que permanece, sempre e já, "o mesmo", idêntico a si mesmo ao longo do tempo. Ela tão pouco se refere, se pensarmos agora na questão da identidade cultural, àquele eu coletivo e verdadeiro que se esconde dentro de muitos outros eus - mais superficiais ou mais artificialmente impostos - que um povo, com uma história e uma ancestralidade compartilhadas, mantém em comum. Ou seja, um eu coletivo capaz de estabilizar, fixar ou garantir o pertencimento cultural ou uma "unidade" imutável que se sobrepõe a todas as outras diferenças - supostamente superficiais. Essa concepção aceita que as identidades não são nunca unificadas; que elas são, na modernidade tardia, cada vez mais fragmentadas e fraturadas, que elas não são, nunca, singulares, mas multiplamente construídas ao longo de discursos, práticas e posições que podem se cruzar ou serem antagônicas. (HALL, 2008, p.108 - destaques do autor).

Destacar que nossas referências identitárias são construídas dentro e não fora do discurso e que as mesmas não são um dado fixo, coerente, estável e permanente é importante porque nos possibilita apreender 0 quanto estão ligadas aos recursos que utilizamos para nos posicionar frente ao outro e no mundo. Razão pela qual acreditamos que só se torna possível falar em identidade se os matizes que a compõem forem concebidos como amálgamas provenientes do entrelaçamento de representações simbólicas demasiadamente amplas que em momento algum devem ser interpretadas como se possuíssem apenas um sentido. Defendemos isso porque:

Os seres humanos são seres interpretativos, instituidores de sentido. A ação social é significativa tanto para aqueles que a praticam quanto para os que a observam: não em si mesma, mas em razão dos muitos e variados sistemas de significado que os seres humanos utilizam para definir o que significam as coisas e para codificar, organizar e regular sua conduta uns em relação aos 
outros. Estes sistemas ou códigos de significado dão sentido às nossas ações. Eles nos permitem interpretar significativamente as ações alheias. Tomados em seu conjunto, eles constituem nossas "culturas". Contribuem para assegurar que toda ação social é "cultural", que todas as práticas sociais expressam ou comunicam um significado e, neste sentido, são práticas de significação. (HALL, 1997, p.26).

Ponderações que nos auxiliam a assimilar que o movimento de constituição de referenciais identitários acaba por refletir menos o que nós somos (estado), e mais o que nos tornamos (processo). Servem, também, como um indicativo de que essa constituição se dá sempre de maneira coletiva e relacional, o que equivale a dizer que a identidade emerge não tanto de um centro interior, de um eu verdadeiro e único, mas do diálogo entre os conceitos, definições, práticas e narrativas apresentadas para nós pelos discursos de uma cultura e pelo nosso desejo (consciente ou inconsciente) de responder aos apelos feitos por estes significados, de sermos interpelados por eles, de assumirmos ou contestarmos as posições de sujeito formuladas por nós e para nós. Além disso, colocam em contraponto o potencial orientador que os processos de socialização primária, aqueles a partir dos quais constituímos nossos laços de enraizamento - os índices de simbolização que apreendemos junto à família, à escola, à igreja, por exemplo - exercem sobre nós no momento em que somos chamados a responder, a nos posicionarmos frete a determinado discurso representacional. Sendo assim, e conforme atesta mais uma vez Stuart Hall:

O que denominamos "nossas identidades" poderia provavelmente ser melhor conceituado como as sedimentações através do tempo daquelas diferentes identificações ou posições que adotamos e procuramos "viver", como se viessem de dentro, mas que, sem dúvida, são ocasionadas por um conjunto especial de circunstâncias, sentimentos, histórias e experiências única e particularmente nossas, como sujeitos individuais. Nossas identidades são, em resumo, formadas culturalmente. (HALL, 1997, p.26-27).

São formadas culturalmente e ancoradas em inúmeras práticas, discursos e esferas da vida social - a família, a escola, a igreja, os sindicatos, o trabalho, o partido político e também as bibliotecas. A identidade é, pois, uma subjetivação ancorada em uma estrutura representacional que se dá a ver, que se expressa por meio de alguma forma de objetivação ${ }^{2}$. Razão pela qual, por mais fluida e maleável que

\footnotetext{
${ }^{2}$ Ancoragem e objetivação são dois conceitos desenvolvidos pelo campo da psicologia social, mais notadamente no âmbito dos estudos acerca das representações sociais. O primeiro indica um exercício de associação em que grupos e sujeitos estabelecem uma relação de proximidade entre aquilo que ainda não está classificado, nem rotulado com imagens, categorias e explicações já conhecidas e aceitas socialmente. Trata-se, pois, de um movimento de categorização das coisas do mundo a partir de configurações simbólicas enraizadas em nossa memória social e subjetiva. A objetivação, por sua vez, refere-se ao ato de transformar a associação abstrata inferida durante o processo de ancoragem em algo quase físico. Em termos representacionais, a objetivação denomina o ato de atribuir/descobrir o aspecto icônico de uma determinada idéia.
} 
possa parecer, requer sempre um ponto de referenciação, uma possibilidade de enraizamento.

Enraizamento, eis outro conceito/operador analítico de grande valor para apreendermos de maneira mais clara os pontos de interconexão e as modalidades de subjetivação que fazem das bibliotecas públicas um lugar de ancoragem, um pólo produtor e revelador de certos discursos identitários. Formulada por Simone Weil, escritora, mística e filósofa francesa, a noção de enraizamento expressa uma forma de estar no mundo. Diz de um conjunto de atividades e experiências de subjetivação que conferem estabilidade e sentido à interação coletiva, bem como às marcas de individualidade que atravessam cada sujeito. Desta feita, os "seres" enraizados são aqueles que enriquecem as práticas da comunidade e fortalecem suas raízes. Que participam de grupos cuja herança do passado alimenta a gramática simbólica moduladora de uma dada noção de cultura. Uma cultura que impede a desagregação dos cidadãos e a paralisia do conhecimento. Em síntese, o que aqui se denomina de enraizamento refere-se ao conjunto de experiências intersubjetivas e de ações concretas que buscam recriar o mundo através de práticas sociais transformadoras. Talvez por isso a pensadora tenha afirmado que:

O ser humano tem uma raiz por sua participação real, ativa e natural na existência de uma coletividade que conserva vivos certos tesouros do passado e certos pressentimentos do futuro. Participação natural, isto é, que vem automaticamente do lugar, do nascimento, da profissão, do ambiente. Cada ser humano precisa ter múltiplas raízes. (WEIL, 1996, p.411).

É, pois, este diálogo entre passado e futuro que faz com que a comunidade não perca suas raízes, ao mesmo tempo em que faculta estabilidade e sentido à vida e às ações das pessoas. Isto porque, o enraizamento pressupõe a participação ativa de um indivíduo entre outros agentes sociais em condições bastante específicas. Condições que podem vir do seio familiar, da escola, do trabalho, da integração à vida religiosa, da cidade, da biblioteca. Onde há enraizamento, a socialização constitui o substrato a partir do qual cada sujeito em particular recebe os princípios da vida moral, intelectual e espiritual que irá nutrir sua existência individual e coletiva. Para tanto, faz-se necessário observar que:

Esta comunicação com o passado não consiste em uma atitude meramente contemplativa. Tampouco assume uma orientação reacionária. Onde os homens espraiam raízes, as lutas e construções dos antepassados, suas ideias e tradições, alicerçam realizações que, por sua vez, irão revesti-las de novos significados. Não se trata de uma importação passiva do mundo pregresso (FROCHTENGARTEN, 2005, p.12).

Nesse sentido, promover o enraizamento não pressupõe isolar um meio social de suas referências externas. Ao contrário, os contatos e as trocas de influências são necessários ao processo de criação de vínculos sociais, afetivos e funcionais desde que esse intercâmbio propicie o 
reconhecimento de uma parte em relação à outra e estimule o respeito à originalidade e à individualidade dos envolvidos. Nas palavras de Frochtengarten (2005, p.13): "em grupos que promovem o enraizamento, estão preservadas as condições de igualdade que garantem aos homens o livre exercício da palavra e de novas fundações: sua aparição diante de outros homens revela sua identidade pessoal e singular".

Portanto, o sujeito enraizado não pode prescindir da socialização, já que é por meio da aparição pública, do diálogo estabelecido com o outro na esfera pública que ele traça e elabora as marcas de uma imagem delineada de si, do outro e do mundo. Talvez por isso Ecléa Bosi (2013, p.196) nos lembre que "enraizar-se é um direito fundamental do ser humano e a negação a esse direito tem consequências graves para a cultura e a vida em sociedade".

Foi isso que também observou Georg Simmel ao apontar que é através das distintas formas de socialização que a vida se renova e atualiza-se. Empreendendo estudos acerca da racionalidade moderna e buscando entender as transformações do espaço social, sobretudo aquele conformado a partir da emergência dos grandes centros urbanos, 0 sociólogo pôde observar que o indivíduo citadino passou a ter suas ações guiadas por referências racionalistas e individualistas que constrangem/solapam aquelas de cunho mais orgânico, afetivo e comunitário que se davam a ver nas sociedades tradicionais. Para o nosso autor, a metrópole preconiza a existência de um sujeito isolado e perdido na multidão. Isso se efetivaria, segundo a perspectiva simmeliana, porque:

O número muito maior de habitantes e transeuntes que caracteriza a grande cidade em relação às formas de convivência do passado, a presença da foule, multidão e multitude, reforçam, paradoxalmente, os sentimentos de solidão, de incompreensão e mesmo de hostilidade entre os indivíduos: o excesso de proximidade torna as formas ${ }^{3}$ cada vez mais estranhas e distantes uma das outras (GAGNEBIN, 2007, p.65).

Distância e estranhamento que só poderiam ser relativizados a partir da constituição de processos dinâmicos de interação social. Processos que transformariam "a mera agregação isolada dos indivíduos em determinadas formas de estar com o outro e de ser para o outro" (SIMMEl, 2006, p.60). Desta feita, ao definir a interação como relações reciprocamente referenciadas que se desdobram infinitamente, posto estar sempre em movimento, o pensador acaba por sinalizar que a sociedade, o tecido social não é senão o resultado dos arranjos e laços estabelecidos por vários indivíduos ligados por ações interativas.

É, pois, a partir desse ponto que os trabalhos de Simmel passam a nos interessar. Partindo do pressuposto de que as formas interativas são

\footnotetext{
${ }^{3} \mathrm{Na}$ sociologia de Georg Simmel, a forma pode ser pensada como sendo os elementos constituidores tanto da cultura como da sociedade que têm sua gênese na própria vida, cujos portadores são os sujeitos. No entanto, segundo ele, à medida que adquirem uma dinâmica própria, as formas passam a submeter, ou buscam submeter esses mesmos sujeitos aos seus desígnios ao invés de assegurar sua autonomia e individualidade.
} 
elos que unem singularidades distintas em uma unidade funcional denominada de sociedade, o mesmo ressalta que seu potencial de agregação só pode ser apreendido e "formalizado" - no sentido de ganhar um conteúdo perceptível - se existir entre tais singularidades o sentimento de "estarem socializados". Isso significa dizer que um mundo social só se constitui onde os projetos de socialização dos indivíduos impulsos, motivos, interesses, desejos e objetivos - podem ser expressos como modalidades autônomas de interação denominadas por ele de sociabilidade.

A sociabilidade, ou o "ato de estar junto", por colocar de lado interesses marcadamente personalistas, se guia tendo como foco a concretização e o sucesso do momento interacional. "Em consequência disso, as condições e os resultados desse processo são exclusivamente o encontro entre as pessoas numa reunião social" (HANKE, 2002, p.3). Assim colocado, esse laço de reciprocidade inscrito nos domínios do sensível, das emoções, do lúdico, dos afetos e também do estético acentua o caráter relacional do conceito simmeliano, cuja recusa das visões totalizadoras do social e o foco na tensão entre forma de socialização e experiências vividas, reforça a dimensão criativa que ampara a concretização e a experimentação das distintas possibilidades de relação social. Condição essa que pode ser exemplificada por meio dos seguintes termos:

Que os homens se olhem uns aos outros, e que eles sejam invejosos entre si; que eles troquem cartas ou almocem juntos; que eles, inteiramente independentes de quaisquer interesses compreensíveis, se achem simpáticos ou antipáticos; que a gratidão de uma obra altruísta enseje um efeito ligador contínuo e ilacerável; que um pergunte ao outro sobre o caminho e que eles se vistam e se enfeitem para os outros - todas as milhares de relações, de pessoa a pessoa, momentâneas ou duradouras, conscientes ou inconscientes, inconsequentes ou consequentes, das quais esses exemplos foram colhidos aleatoriamente, atam-nos incessantemente. A cada instante esses fios são tecidos, desatados, retomados, substituídos por outros, entrelaçados a outros. (SIMMEL, 1908, p. 31-35 apud WAIZBORT, 2001, p.94).

Portanto, o conceito de sociabilidade se apresenta para nós, tal qual o de enraizamento, como importante operador analítico para compreendermos as situações vividas socialmente, inclusive aquelas que acontecem no interior de uma biblioteca pública. Situações nas quais o aspecto relacional "se impõe e ganha existência para além de seus objetivos, onde formas institucionalizadas sofrem torções e modificações, conteúdos são revistos e finalidades são alteradas" (FRANÇA, 2012 - nota de aula).

Sendo assim, atar-se ao mundo e nele estabelecer relações de reciprocidade com o outro, relações que podem se reverberar e se transformarem em pontos de referência a partir dos quais certas representações identitárias são delineadas, disseminadas e atualizadas é apenas uma das muitas possibilidades interativas que a conjunção entre 
sujeitos enraizados e em permanente processo de interação/socialização acaba por promover.

Constatação que nos leva, mais uma vez, à questão que orienta toda a nossa discussão, a saber: como podemos explicar o apontamento feito pela interlocutora de Mechèle Petit? Para sermos mais precisos, como podemos aproximar o conceito de identidade do universo das bibliotecas públicas? Tais instituições são mesmo instâncias capazes de facultar o enraizamento, a sociabilidade e a constituição de nossas representações/referências identitárias? Buscamos responder a tais indagações lançando mão dos testemunhos de dois usuários da Biblioteca Pública Estadual Luiz de Bessa. Mais especificamente, da história de vida de um senhor de 59 anos que, depois de aposentado e de maneira autodidata, encontrou no acervo de coleções espaciais da Biblioteca um espaço para seus estudos e um lugar para exercitar sua vocação socializante, e, também, do testemunho de um segundo sujeito que teve as relações mantidas com o mundo e a imagem de si completamente alteradas após começar a frequentar a Hemeroteca da Luiz de Bessa.

\section{Biblioteca pública e identidade: elaborações intersubjetivas enraizadas em torno da Luiz de Bessa}

Fundada em Belo Horizonte no ano de 1954 por meio da Lei Estadual no. 1087, sancionada em 2 de junho por Juscelino Kubitschek, a Biblioteca Pública Estadual Luiz de Bessa ${ }^{4}$ possui por função primária servir de centro de memória da capital mineira, reunindo, preservando e divulgando os registros da história local, de modo a valorizar a identidade cultural belohorizontina, se reportando, de modo mais geral, ao universo simbólico de todo o Estado. Está localizada em uma das regiões mais nobres da cidade e recebe cerca de 390 mil usuários por ano, aos quais presta uma série de serviços: empréstimo domiciliar, sala de estudos e leitura, carro-biblioteca, um setor especializado em acolher deficientes visuais, uma sucursal destinada ao público infanto-juvenil e também o serviço de caixa-estante que leva livros e a oportunidade de leitura a creches, asilos, prisões e espaços alternativos muito diferentes de suas fronteiras.

Tornou-se a responsável por manter coleções raras e de grande valor para o estudo, a divulgação e a representação da história e do "modo de vida mineiro". Em seu acervo destacam-se a Coleção Mineiriana"; a Coleção Rita Adelaide ${ }^{6}$ e os jornais e revistas que

\footnotetext{
${ }^{4}$ Antônio Luiz de Bessa nasceu em Amarante, Portugal, em 12 de abril de 1894. Veio para o Brasil em 1906, instalando-se em Juiz de Fora, onde se formou em ciências comerciais. Foi também jornalista, exercendo carreira tanto nessa cidade quanto em Belo Horizonte, onde se tornou redator-chefe do Estado de Minas e da Folha de Minas. Em sua pequena bibliografia se destacam o livro História Financeira de Minas Gerais em 70 anos de República e uma tese apresentada em Santiago do Chile, intitulada Função Nacional do Município. Além de tais obras, publicou um pequeno opúsculo denominado Minas Gerais, uma economia em expansão. Exerceu diversas funções públicas e redigiu correspondências, mensagens e discursos para governadores e secretários do Estado. Veio a falecer na capital mineira em 16 de fevereiro de 1967.

${ }^{5}$ Criada através do Decreto no. 11.996 , de 05/08/1969 por uma comissão de intelectuais mineiros, a Coleção Mineiriana tem por finalidade compor um acervo de obras sobre Minas Gerais, sua história, letras, artes, ciências da terra e do homem, bem como desenvolver ações de divulgação da cultura do estado, editar e promover publicações de obras relacionadas ao tema. Foi tentando dinamizar essas ações que, em
} 
pertenceram à Hemeroteca Pública de Minas Gerais, hoje incorporado ao patrimônio documental da Luiz de Bessa.

Ao longo de seus 60 (sessenta) anos de atuação, inúmeros usuários se formaram como leitores tendo por referência as coleções, atividades e o espaço de sociabilidade que se criou no perímetro de suas dependências. Em virtude disso, ocupa hoje um lugar privilegiado na vida e na memória de diversos sujeitos, congregando em torno de si um universo de representações simbólicas multivariadas que, em um plano mais geral, fomenta a mobilização de diversos quadros de sentido cuja síntese ampara e dá a ver a formulação de um discurso identitário intersubjetivo em estreito diálogo com experiências objetivadas e enraizadas no plano coletivo.

Sendo assim, e em linhas gerais, o que nossa pesquisa objetivava identificar eram histórias de vida marcadas em algum momento pelas experiências vivenciadas na e a partir da Luiz de Bessa, visando-se, posteriormente, apreender se a mesma constitui-se como um lugar de produção e de ancoragem intersubjetiva de discursos identitários. Em função disso, depois de prolongada imersão no cotidiano da instituição e de conversas com bibliotecários e usuários da casa, selecionamos sete sujeitos $^{7}$ dispostos a nos conceder seu depoimento e a refletir sobre suas distintas modalidades de apropriação daquele espaço, além de analisarem a presença simbólico-afetiva que a Biblioteca ocupa no contexto geral de suas biografias e do conjunto de referências que mobilizam/orientam cada uma dessas histórias de vida.

Definida intencionalmente, a seleção dos depoentes levou em consideração os seguintes critérios: tempo em que é usuário da Biblioteca, frequência com que utiliza ou participa das ações desenvolvidas pela instituição e, principalmente, o reconhecimento por parte dos sujeitos de que a Luiz de Bessa exerce uma força de afetação sobre sua história de vida. Além desses, dois outros critérios foram estabelecidos, a saber: a amostra constituída deveria representar a diversidade de indivíduos que se relacionam com os distintos setores da Biblioteca e, para não se correr o risco de, ao final do trabalho, consolidarmos um discurso unificado e pacificado, pelo menos um dos nossos interlocutores deveria se declarar alheio a essa afetação.

Seguindo tais disposições e constatando que a contribuição fundamental para o desenvolvimento do estudo seria dada pelos depoentes, além de que os dados a serem tratados referir-se-iam a um trabalho intersubjetivo de elaboração de memórias e vivências pessoais

03/02/1970, o governo do Estado sancionou o Decreto no. 14.314, instituindo a obrigatoriedade de se processar a remessa de publicações oficiais à biblioteca Luiz de Bessa para serem incorporados à coleção.

6 Composta por 1.305 volumes, representa a biblioteca pessoal do jurista e bibliófilo Tancredo Martins e recebeu este nome em homenagem à sua mãe. Destaca-se por seu conteúdo, raridade, beleza e singularidade das encadernações, ilustrações e iluminuras. Os títulos tratam principalmente de religião, literatura, história, filologia e obras de referência. Também figuram no acervo livros sobre artes, botânica e geografia.

7 Defendida originalmente como tese de doutoramento, a pesquisa à qual fazemos remissão contou com a colaboração de 7 sujeitos, 2 mulheres e 5 homens, contudo, no contexto do presente artigo, devido às limitações características dessa modalidade textual, serão sintetizados e analisados os depoimentos de apenas dois desses usuários. 
cujo marco desencadeador é a própria Biblioteca, optamos por definir como diretriz orientadora de nossas ações interpretativas os parâmetros e preceitos metodológicos advindos das pesquisas com histórias de vida. Estratégia de formalização do conhecimento que busca conjugar questões de ordem subjetiva com experiências concretas da vida social, aferidas através das recorrências, dos silêncios e dos desvios projetados ao longo da captação dos testemunhos. Além disso, como a natureza desse método não se revela unilateral, uma vez que considera os elementos racionais, mas também o desejo, os sentimentos e as emoções que atravessam a relação entre o individual e o social, tornou-se manifesto para nós o quanto seus desdobramentos analíticos poderiam nos auxiliar a melhor compreender de que forma a Luiz de Bessa aparece referenciada nos discursos de nossos interlocutores.

Explicitado o panorama geral da pesquisa, é importante que se faça aqui uma observação: no decorrer das entrevistas verificou-se a impossibilidade de se separar, como se fossem formas estanques, sujeito e objeto. Percebeu-se ainda que, quando nos posicionávamos enquanto pesquisador, formulando as perguntas e solicitando maiores detalhes sobre uma temática específica, nossa intervenção despertava ou redirecionava o exercício mnêmico dos depoentes. Razão pela qual, visando potencializar a evocação e a transmissão das lembranças, a relação entre pesquisador e usuário se mostrou em muitos momentos um processo interativo pautado por descobertas mútuas. Assim, recorremos a uma estratégia dialógica de interação e comunicação em que ao mesmo tempo pudéssemos ser ouvinte e interlocutor dessas histórias/memórias reconstituídas. Isso se deve ao caráter da nossa pesquisa e a seu aspecto eminentemente qualitativo.

Antes dos testemunhos serem coletados, processou-se uma conversa inicial com os depoentes para explicá-los o teor da pesquisa e avaliar a disponibilidade de participarem ou não. Os dados foram coletados mediante a realização de entrevistas semi-estruturadas. Como dispositivo orientador, elaborou-se um conjunto de perguntas que permitiram aos nossos interlocutores refletirem sobre sua formação enquanto sujeitos históricos e sobre as relações que mantém/mantinham com e no espaço público de Belo Horizonte (atividades, estratégias de mobilização e relações prático-afetivas). As questões possibilitavam ainda que os depoentes analisassem o lugar ocupado pela Biblioteca Luiz de Bessa - dimensões históricas, simbólicas e estruturais - em todo esse processo formativo-relacional.

O cuidado ético relativo às histórias de vida e à pesquisa como um todo foi fundamental. Desde o consentimento para a realização das entrevistas até o tratamento dos resultados obtidos por meio delas. Todas foram gravadas em local e data escolhidos pelo usuário e a transcrição efetuada respeitando-se a estrutura discursiva e os vícios linguageiros dos sujeitos em foco. Dado à sinuosidade do trabalho mnêmico, por vezes foi necessário deslocar um trecho ou outro da estrutura narrativa original, 
apenas para aproximá-lo de um enquadramento contextual mais apropriado àquilo que estava sendo perguntado.

Apresentadas as diretrizes metodológicas que ampararam a definição da amostra e a elaboração dos instrumentos de coleta de dados, passamos agora à síntese e à análise dos testemunhos colhidos tendo-se por referências os depoimentos de dois usuários cujas histórias de vida mostram-se profundamente marcadas pelas relações mantidas com a Biblioteca Pública Estadual Luiz de Bessa - seu espaço físico, acervos e atividades - e com os demais sujeitos responsáveis por sua dinamização e funcionalidade - profissionais e outros frequentadores da instituição. Para tanto, ao longo desse processo interpretativo serão recuperadas as formulações teórico-conceituais elaboradas na seção anterior com 0 intuito de subsidiar nossa argumentação de que as bibliotecas públicas são pólos mobilizadores de referenciais identitários, cuja força de afetação intersubjetiva e social se dá a ver tanto através das representações simbólicas responsáveis por lhe conferir visibilidade e justificar a execução de certos serviços e ações práticas, quanto pelos usos/múltiplos usos que cada sujeito lhes impõe.

O primeiro depoente ao qual daremos voz chama-se José F. e nasceu em Conselheiro Lafaiete. Filho de pai ferroviário e mãe professora de escola rural, aprendeu a ler em casa. Sempre frequentou escolas públicas e diz ter sido um bom aluno, visto acreditar que, por ser filho de professora, deveria dar-se ao exemplo. Contudo, no ginásio, não "levou a coisa a sério" e foi reprovado, "e nessa oportunidade teve uma professora lá que me chamou, disse que eu era o mais burro da turma - "você é o mais burro da turma! Eu nunca vi gente burra assim" -, disse que eu não daria carreira" (JOSÉ F, 2013, p.08). Lembrança que ainda expressa com certo rancor.

Não havia bibliotecas nessas escolas por onde passou, a leitura era promovida e incentivada pelos professores. Para suprir a falta de incentivo em seus primeiros anos de escolarização, ia à biblioteca pública da cidade. Veio para Belo Horizonte no final de 1972, 1973, não se recorda precisamente, mas diz que o intuito era tentar a escola técnica. Como o dinheiro "era difícil", foi morar em uma república de dois cômodos, divididos por 12 pessoas. Mesmo assim, "nesse período eu estudei tudo, fiz o que tinha que ter feito, melhorei minha vida e essa pessoa que me chamou de burro, eu levei as provas pra ela ver, então eu fui crescendo desse jeito" (JOSÉ F, 2013, p.08)..

Frequentava pouco a Praça da Liberdade ${ }^{8}$, e só veio a conhecer a Luiz de Bessa quando foi convidado para trabalhar no centro de pesquisas

\footnotetext{
${ }^{8}$ Marco cultural da capital mineira, sua construção iniciou-se paralelamente ao processo de fundação da cidade (1895-1987). Foi criada para abrigar a sede do poder político do Estado, notadamente o Palácio do Governador e suas secretarias. Seu conjunto arquitetônico e paisagístico foi tombado pelo IEPHA Instituto Estadual do Patrimônio Histórico e Artístico - em 02 de junho de 1977. Além de sua importância política, destaca-se no cenário urbano da cidade por sua apropriação enquanto espaço de sociabilidade e cultura, especialmente a partir da consolidação do Circuito Cultural Praça da Liberdade, um conglomerado de equipamentos culturais abertos à freqüentação pública entre os quais se destacam o Centro Cultural Banco do Brasil, o Museu das Minas e do Metal, o Memorial Minas Gerais, a Casa Fiat de Cultura, o Palácio da Liberdade e também a Biblioteca Pública Estadual Luiz de Bessa, por isso sua constante presença na fala e no imaginário de nossos depoentes.
} 
da Vale, apesar de ter ficado lá por pouco tempo, já que preferiu mudarse para a Cemig, empresa que Ihe possibilitou conhecer "até os Estados Unidos". O vínculo com a Biblioteca só se estreitou depois da aposentadoria. Casado, mas sem filhos, quis saber, de maneira autodidata, "a origem das palavras, a origem das letras", e se aprofundar no estudo da historiografia e cultura mineira. Em suas palavras:

Aí eu me interessei pelos jornais da época e fui lendo todos que eu podia ler, todos que eu tinha acesso. Então eu via como é que o povo vivia, o quê que se comia, o quê que bebia né!, queria saber tudo..., tudo: o quê que o povo fazia, o quê que tinha de relação de uma cidade com a outra, como é que uma criança aprendia a ler há tantos anos atrás, eu queria saber como é que se fundou a primeira escola pública, a primeira escola de letras, as relações entre as capitanias, tudo, tudo que você puder pensar eu fui ver, tudo! (JOSÉ F, 2013, p.09).

Hoje se declara um devotado usuário da Mineiriana. Frequenta esse espaço diariamente, exceto às quintas-feiras, dia em que ajuda sua esposa com os afazeres da casa. Foi nesse setor que conheceu sua mais recente paixão literária, que o mobilizou, inclusive, a aprender português arcaico: "conheci aqui o Rafael Bluteau", o cara é o máximo, ele é..., é o caminho das índias literárias, é o oitavo elemento, não tem ninguém na frente dele, então ele está no Everest, subiu num tijolo braúna e está acima de qualquer suspeita, ele é o caminho das índias literárias" (JOSÉ F, 2013, p.12-13). Relata ter lido todos os 8 volumes, empreitada levada a cabo ao longo de dois anos ininterruptos de leitura e pesquisa.

Contudo, é preciso frisar que sua chegada às coleções especiais da Biblioteca não se deu de maneira tão pacífica. Vindo de outra cidade e sem muita experiência com atividades de pesquisa, pensava que as coleções especiais estavam voltadas exclusivamente para atender às demandas de um público selecionado, formado, em sua maior parte, por acadêmicos e especialistas. Portanto, e considerando-se um autodidata, demarca que:

Pra "mim" chegar aqui não foi fácil não, porque a gente não sabe..., aqui parecia ser um lugar selecionado, muito de elite e eu fiquei com o pé atrás: como é que eu vou chegar? Chegar sozinho? Eu não sou orientado por ninguém! Vou ficar perdido! Eu sou um amador... (JOSÉ F, 2013, p.11).

Tendo sido bem acolhido pelos funcionários da instituição, tornou-se hoje um defensor e um amante devotado das coleções especiais da Luiz de Bessa, tanto que, em certo momento de seu relato, chega a afirmar: "já tem uns cinco anos que eu tô aqui agarrado e tá difícil de sair (risos)!" (JOSÉ F, 2013, p.13). É por isso que considera a Mineiriana "o máximo", um verdadeiro acervo histórico e de referência. Conforme sustenta,

${ }^{9}$ BLUTEAU, Raphael. Vocabulario portuguez \& latino: aulico, anatomico, architectonico ... Coimbra: Collegio das Artes da Companhia de Jesus, 1712 - 1728. 8v. Além dos oito volumes, o dicionário conta com dois outros volumes suplementares. Nestes suplementos, existem verbetes novos e também informações adicionais aos verbetes existentes. 
"acima disso só a Biblioteca Nacional" (JOSÉ F, 2013, p.10). Mas há uma situação que lhe deixa frustrado e descontente: o pouco uso das coleções especiais por parte de outros pesquisadores e de sua depreciação em relação a outros centros de referência mantidas por entidades estrangeiras. Tanto que, em sua defesa, compara os fundos bibliográficos da Luiz de Bessa a um diamante que está escondido: "é um diamante que está escondido, tá escondido! Aqui podia estar cheio de pessoas; as escolas, os professores, acho que tem pessoa que tem medo de vir cá, tem medo. A história nossa tá aqui dentro" (JOSÉ F, 2013, p.15-16).

Como se vê, além de um lugar de leitura e estudo, a Biblioteca, e em especial o setor de coleções especiais, é para José F. um espaço que o faz se sentir bem, que lhe dá vontade de continuar a aprender mesmo depois de aposentado. Representa, ainda, um refúgio contra o ócio, mais que isso, um espaço de sociabilidade e de interação permanente com outros usuários da Luiz de Bessa: "nessa minha lida eu converso com todo mundo, sei conversar com as pessoas, as pessoas acham interessante. [...] Conheço pessoas diferentes, tenho o prazer de falar da biblioteca pras pessoas, mostrar o que eu to lendo, não escondo nada de ninguém" (JOSÉ F, 2013, p.18-19).

Ao pesquisar na Mineiriana, nosso interlocutor consegue ocupar seu tempo livre, satisfazer seus anseios por conhecimento e exercitar sua vocação socializante. Diz que todos os dias descobre "coisas novas" e conhece pessoas com as quais pode dividir aquilo que aprendeu. Trata as bibliotecárias "a ouro em pó" e os livros como verdadeiras preciosidades. Sente-se tão integrado aos seus espaços que, ao fim de sua narrativa, nos diz que poderia falar muitas outras coisas sobre suas experiências com aquele espaço, com os serviços e sujeitos que o mesmo lhe proporcionou conhecer. Como ele mesmo demarca, poderia falar "sem ter hora pra parar":

Aqui me preenche tudo igualzinho, às vezes chega um pesquisador que eu vejo que ele tem dificuldade, eu educadamente inquiro, ajudo, mostro..., é isso que eu faço. [...] As bibliotecárias aqui são tratadas a ouro em pó, porque ouro em pó não tem mistura. A gente tem que ver as pessoas como ouro em pó, não tem sujeira, não tem falcatrua, não tem falsidade. Nessa minha lida eu converso com todo mundo, eu converso com qualquer um. [...] Então eu fico satisfeito e a gente podia conversar muito mais, não tem hora pra parar não (JOSÉ F, 2013, p.18-21).

Falar sobre a biblioteca e de como ela influenciou em seu percurso formativo é também um dos prazeres de Luiz $\mathbf{Q}$. Natural de Carangola, é licenciado em letras pela Universidade Federal de Minas Gerais, com habilitação em português-francês. Obteve, nessa mesma universidade, os graus de mestre e doutor em Estudos Literários. Nasceu em 1964 e é o sétimo filho de um total de nove irmãos. Seu pai era funcionário público e a mãe professora primária. Aprendeu a ler em casa e isso servia como uma espécie de exibição para as visitas, "quando chegava visita em casa, 
a mãe dizia - "Vem, senta aqui e mostra como você já lê!" (LUIZ Q., 2013, p.02).

Sua iniciação literária se deu através dos livros da "Série VagaLume $^{10 "}$ ". Depois, passa a ler desordenadamente tudo que "caía em suas mãos". Mesmo tendo aprendido a ler muito cedo, não frequentava a biblioteca de sua escola porque, segundo ele, "não havia estímulo para isso". Situação semelhante ao que aconteceu com a biblioteca pública de Carangola, "um espaço pequeno e que não funcionava com regularidade".

Afirma não se lembrar do primeiro livro que leu, mas se recorda de ter sido um presente concedido por algum familiar para amenizar uma doença que havia contraído quando criança, sarampo talvez. Adverte que o mesmo tinha mais gravuras que texto, o que o levou a lê-lo e relê-lo várias vezes. Dessa fase, não se esquece da descoberta do "Círculo do Livro $^{11 ",}$ que considera o elemento desencadeador de sua compulsão por comprar livros:

Quando eu descobri o Círculo do livro eu me lembro que eu comprava livros, eu recebia a revista, escolhia e, na medida do possível, eu ia comprando por meio de pedido. Eu pedia o meu pai ou minha mãe ou então meu avô que tinha uma loja de fotografias. Eu ficava lá com ele, ajudava ele, ele me dava, não era salário nem mesada, mas ele me dava um dinheiro e esse dinheiro eu usava para fazer os pedidos do círculo do livro (LUIZ Q., 2013, p.07).

Luiz Q. mudou-se para Belo Horizonte quando completou 18 anos, veio prestar vestibular e graduar-se em letras. Quanto à Luiz de Bessa, a mesma só passa a ser uma referência importante para o depoente no momento da transferência dos fundos da Hemeroteca para a coleção da Biblioteca Pública. Isso porque, o mesmo procura em jornais e revistas antigos informações que possam subsidiar seu trabalho de pesquisa sobre os espaços de sociabilidade LGBT em Belo Horizonte, especialmente entre as décadas de 1940 e 1980. Já publicou um livro sobre o assunto e pretende escrever outras duas obras. Mantém contato com a instituição há dez anos e, ultimamente, tem ido até lá todas as sextas-feiras das oito às dezoito horas. "Ao longo desse tempo, passaram pelas minhas mãos todos os jornais desde 1950, eu já finalizei a década de 70 e tô começando a década de 80. Então trinta anos eu já peguei, já folheei um a um, dia a dia, mês a mês, ano a ano pra buscar essas informações" (LUIZ Q., 2013, p.02).

Para ele, a imagem que sintetiza sua chegada à Biblioteca é a de uma pungente frustração: o prédio era mal cuidado, havia pouco espaço para leitura e quase nenhum investimento público na manutenção de seus setores e acervos. Com o passar dos anos visualiza uma mudança de perspectiva e, em seu discurso, referenda a importância social da Luiz de

${ }^{10}$ A Série Vaga-Lume é uma coleção de livros lançada pela editora Ática a partir do ano de 1972. Sua obras, voltadas para o público infanto-juvenil, constituíram-se em um marco de vendagem no âmbito do mercado literário e livreiro do país.

${ }^{11}$ Editora que vendia suas obras por meio de um "sistema de clube", onde a pessoa era indicada por algum sócio e, a partir disso, recebia uma revista quinzenal com dezenas de títulos a serem escolhidos. 0 novo sócio teria então a obrigação de comprar ao menos um livro no período. Embora essa estratégia comercial tenha rendido bons lucros, a editora encerrou suas atividades no final da década de 1990. 
Bessa para Belo Horizonte, bem como em sua própria trajetória de vida. Estabelecendo um contraponto com as bibliotecas universitárias, 0 depoente reforça seu caráter de instituição pública e ressalta a variedade dos acervos ali disponíveis como marco de fundamental relevância para a cidade:

A Luiz de Bessa é fundamental na cidade. Ela é a única biblioteca, até onde eu sei, aberta ao público com um acervo variado, não só de livros, mas também de jornais e de revistas. Você tem as bibliotecas universitárias, mas elas acabam não atendendo à mesma função que uma biblioteca pública deveria atender. Então eu acho que é fundamental, ela precisa existir, ela precisa continuar existindo (LUIZ Q., 2013, p.14).

Precisa continuar existindo não só em função da amplitude de seus acervos, da diversidade de seus serviços ou da monumentalidade de seu prédio, mas, sobretudo, pela importância que ela possui na história de vida de seus leitores e usuário. Para Luiz Q. o contato com essa instituição foi tão relevante que o trabalho de pesquisa na Hemeroteca resultou em uma sensível mudança na sua maneira de ler jornal e isso impactou diretamente na forma como hoje pensa o jornalismo, área de conhecimento em que atua profissionalmente. Dito em suas próprias palavras:

O manuseio dos jornais na hemeroteca acabou também mudando a minha forma de ler o jornal. Mudou no sentido, assim, ler dez, vinte, trinta anos de jornais acaba te dando..., você acaba criando alguns mecanismos internos de reflexão, de ver como que o jornal vai mudando ao longo do tempo, não só na sua diagramação, mas na forma de trabalhar as informações, na forma de dar atenção a determinados temas ou a determinadas áreas. Enfim, isso acaba te levando a pensar em como que o jornal tá presente na sua vida, como que o jornal acaba te conduzindo a pensar de certa forma, acaba guiando uma forma de ler que você não tem, por exemplo, com o livro, com a obra literária. Então isso também foi importante. Ganhar essa consciência na frequência cotidiana da hemeroteca foi importante também pra me fazer pensar sobre o jornalismo (LUIZ Q., 2013, p.16).

Foi importante também para tecer novas redes de sociabilidade. Não diz que a Luiz de Bessa é sua casa, mas que, de tanto frequentá-la, adquiriu tamanha familiaridade que acabou despertando um sentimento, uma atenção diferente para com ela. Em suas recordações, a Biblioteca ganha feições de um lugar especial porque, conforme ele mesmo ressalta, consegue perceber sua própria história de vida, tal qual sua trajetória de formação intelectual se refletindo na história da instituição e nas relações mantidas com os funcionários que ali trabalham. Ao fim de seu depoimento, eis o que Luiz Q. nos declara:

Enfim, eu não direi, eu não chegaria ao exagero de dizer que a biblioteca é a minha casa. Não é! Esse tipo de metáfora pra mim é muito exagerada, mas hoje eu possuo certa familiaridade com a 
biblioteca. Por exemplo, seu Milton, que é um dos porteiros que se revezam ali na portaria, ele me cumprimenta pelo nome, eu o cumprimento pelo nome também, aí quando eu chego no balcão pra pegar a chave pro escaninho a Helena me cumprimenta pelo nome. Quando eu subo, o Jairo, o Marcos, a própria Eliani, agora eu esqueci o nome, a funcionária, a bibliotecária que trabalha com a Eliani..., atualmente a Priscila que é a responsável pela hemeroteca, antes era a Marina, antes da Marina era a Tais, antes da Tais era uma que não sei o nome, mas que foi quando eu comecei a frequentar lá na Assis Châteaubriant, mas que eu via ela lá, ela me via, mesmo que eu não saiba o nome dela, criar essa espécie de história da instituição, mesmo que seja uma história particular a partir do contato semanal que eu tenho com a instituição, por meio dessa certa familiaridade de construir uma história minha lá dentro e ver um certo reconhecimento, um certo carinho que eles têm comigo, isso sem dúvida é muito importante e agradável pra mim (LUIZ Q., 2013, p.16).

Modalidades de apreensão que, somadas àquelas expressas no primeiro depoimento, nos permitem assinalar alguns enquadramentos sociais e simbólicos responsáveis por conferir à Biblioteca Pública Estadual Luiz de Bessa o status de lugar de ancoragem identitária. O primeiro deles indica que sua presença nas histórias de vida dos nossos depoentes está diretamente relacionada às representações que demarcam sua função de lugar de leitura, de educação, memória e cultura, mas também como espaço de enraizamento e sociabilidade. De fato, foi através dos acervos e atividades por ela dinamizados que nossos entrevistados conseguiram potencializar sua formação enquanto leitores, além de travarem contato com os dispositivos informacionais necessários à ampliação de seus universos culturais e educacionais, chegando mesmo a impactar em seu exercício profissional.

Com isso, e não por acaso, além de espaço de estudo e leitura, aparece de maneira recorrente na fala desses usuários uma compreensão de que a Biblioteca desempenha importante trabalho de conservação, organização e disseminação da memória, do patrimônio cultural e intelectual, bem como da história belo-horizontina, mineira e nacional. Outro enquadramento marcante é aquele que apresenta a Luiz de Bessa como território de sociabilidade e enraizamento, um refúgio em meio à vida tumultuada da metrópole, onde se pode encontrar com os amigos e fazer novas amizades, descansar, ler um jornal, trocar ideias sobre uma exposição artística, tomar um cafezinho e compartilhar sonhos, desejos ou outras necessidades pessoais.

Nestes termos, através desses dois testemunhos, nos tornamos capazes de evidenciar a importância intersubjetiva ocupada pela Luiz de Bessa no que diz respeito à composição do quadro representacional que modula as referências identitárias dos dois usuários aqui em foco, bem como apontarmos que tais referências possuem a capacidade de transcender o domínio individual, posto apontarem para um processo de validação coletiva dos seus distintos atributos e funções sociais. 
Sendo assim, ao refletirem sobre suas próprias histórias de vida e os múltiplos pontos de interconexão que as ligam à Luiz de Bessa, nossos dois depoentes elaboram variados quadros de sentido que nos permitem apreender como a Biblioteca instaura-se enquanto referência moduladora no processo de produção intersubjetiva dos discursos identitários acionados por nossos interlocutores.

Para José F. a Biblioteca Pública define-se como lugar de acolhimento, de aprendizado e de socialização, razão pela qual, mesmo após aposentado, continua indo até lá todos os dias, exceto às quintasfeiras. Também por isso defende um maior reconhecimento social para a instituição, suas coleções especiais e para o trabalho dos bibliotecários que, segundo seu testemunho, deveriam ser tratados como "ouro em pó". Modalidade de compreensão que não se distancia muito das imagens e referências acionadas por Luiz Q., para quem o trabalho contínuo de pesquisa na Hemeroteca redefiniu até mesmo a forma como ele pensa e exerce suas atividades profissionais. Frequentador assíduo da Luiz de Bessa, constituiu ali um núcleo de relações sociais capaz de fazer da leitura de jornais antigos uma prática prazerosa e menos maçante, razão pela qual, mesmo não dizendo que a Biblioteca seria como sua casa, deixa claro que as pessoas com quem ele se relaciona e se relacionou ao longo desses mais de 10 anos lhe permite refletir sobre a história da instituição, tanto quanto repensar e demarcar os pontos de ancoragem e objetivação representativos de sua trajetória de vida.

Quadro afetivo e representacional que acaba por conferir uma resposta positiva à nossa questão inicial, comprovando que as bibliotecas públicas são mesmos espaços que participam ativamente no processo de produção de referenciais identitários. Produção que não está ancorada apenas no exercício de suas funções básicas - lugares de leitura, de educação, memória, informação e cultura -, mas principalmente nas experiências vivenciadas por cada sujeito em seu interior. Por isso, tornase indispensável termos por consideração que só a parti do momento em que passamos a entender tais instituições como espaços de enraizamento e sociabilidade, cujas ações práticas, aliadas à sua força simbólica, refletem as diferentes pulsões da vida social é que nos tornamos aptos a demarcar seu caráter de biblioteca pública, de esfera capaz de movimentar, afetar e redimensionar as referências intersubjetivas acionadas por seus distintos usuários quando estes são chamados a elaborarem um discurso, uma imagem sintetizadora de si e da sua história de vida. Em outros termos, de pensarem, identificarem e expressarem seu lugar no mundo.

\section{Considerações finais}

Simone Weil referendou em sua obra a importância do enraizamento para a alma humana salientando que a participação ativa na esfera do social converte-se em elemento preponderante para a constituição dos quadros de sentido que orientam tanto as ações coletivas, quanto as 
experiências intersubjetivas responsáveis por conferir estabilidade às nossas vidas particulares. Nessa perspectiva, o sujeito enraizado mostrase apto a reconhecer que sua existência individual tem como ponto de ancoragem os princípios morais, intelectuais e espirituais instituídos pelo agrupamento cultural ao qual pertence e que sua assimilação se dá através das dinâmicas de interação vivenciadas, sobretudo, no espaço público.

Por não ser um processo coercitivo, mas sim de permanente negociação, esse movimento em torno da criação de vínculos de socialização e enraizamento acaba por amparar a conformação dos gestos e discursos que posicionam os sujeitos no mundo, que revelam maneiras peculiares de intervenção e apropriação da realidade. É em razão disso que nos tornamos capazes de apreender a força simbólica que tal movimento exerce sobre a elaboração das referências moduladoras de nossas representações identitárias.

Portanto, mesmo que contemporaneamente a noção de identidade seja apresentada como um constructo fluido e maleável, que dispensa categorizações e rótulos voltados para sua demarcação, o fato de sermos seres sociais em busca de enraizamento nos impõe a necessidade de engendrarmos laços de solidariedade a partir dos quais nossos discursos e ações possam encontrar ressonância, desvelando quem somos e o que nos tornamos. Desvelamento que pode acontecer tendo por referência inúmeros contextos de significação: a família, a congregação religiosa, a escola, os grupos de trabalho ou, conforme postulado por esse estudo, também através das experiências vivenciadas no interior e a partir das bibliotecas públicas.

Processo que, no caso de tais instituições, pode ser explicitado a partir de dois níveis distintos, mas não indissociáveis: o nível coletivo e o intersubjetivo. No primeiro deles a biblioteca pública se apresentaria como espaço por meio do qual são produzidas, organizadas e disseminadas certas representações que povoam/alimentam a constituição de uma memória comum e coletivamente compartilhada entre seus usuários e leitores. O foco aqui é o acervo, o prédio, os serviços e ações que definem um lugar social e singular para cada uma dessas instituições. Estamos falando então de discursos identitários formulados a partir de um repertório amplo de significação cujos elementos desencadeadores são os fatos históricos, as correntes ideológicas, as diretrizes políticas e os pressupostos simbólicos que se materializam em torno delas. Ou seja, trata-se de uma identidade construída espacial e temporalmente que não tem por referência a satisfação e os desejos de um sujeito específico, mas sim uma preocupação com a salvaguarda dos insumos culturais que orientam e expressam a conduta e os modos de vida de toda a comunidade na qual a mesma se insere.

Neste sentido, a organização de coleções especiais, a realização de visitas guiadas ao acervo, a concepção de exposições relacionadas à sua historicidade, bem como sobre a vida de personalidades que frequentam/frequentaram seus espaços, além da constante busca por 
revitalização de suas dependências são algumas das muitas estratégias utilizadas pelas bibliotecas públicas para promoverem graus variados de identificação com seus usuários. Identificação que, ao ser ancorada em adjetivações como "lugar de memória", "catedral do conhecimento" e "templo do saber", acaba por refletir o reconhecimento de sua impregnação social.

Mas há ainda uma segunda perspectiva que nos permite pensar a relação entre biblioteca pública, identidade, enraizamento e sociabilidade. Estamos falando das referências intersubjetivas que seus usuários elaboram no momento em que analisam o poder de afetação que as mesmas exercem em suas vidas individuais. Influência que se mostra diretamente imbricada às interações e práticas de sociabilidade vivenciadas de maneira particular por cada sujeito no âmbito desses espaços. Elaborações forjadas tanto a partir das coleções e serviços ali disponibilizados, quanto das experiências trocadas com outros leitores e agentes que mobilizam e conferem dinamicidade às ações que nela se desenvolvem.

Portanto, visualizar a constituição de referenciais identitários elaborados intersubjetivamente a partir das bibliotecas públicas requer ampliar o conjunto de atributos que tradicionalmente são utilizados para definir suas funções sociais básicas e pensá-las como um espaço vivencial. Com isso, a preocupação aqui não é entender que motivos circunscrevem a formatação de um acervo ou um conjunto de serviços específicos, mas sim os usos que distintos usuários impõem sobre os mesmos. Nestes termos, o que deve ser observado é a mescla entre valores, desejos e necessidades particulares que levam determinado sujeito a frequentar espontaneamente tais lugares. Não só frequentar, mas criar laços de enraizamento e estabelecer relações interativas que permitam a cada indivíduo formular/apreender intimamente as razões e os pontos de referências que interconectam sua história de vida a uma dessas instituições bibliotecárias.

Laços de enraizamento e relações interativas que fomentam o encontro entre as referências pessoais de cada sujeito e o universo mais amplo das representações que modulam a própria vida social. Com isso, as bibliotecas públicas transformam-se em territórios privilegiados para que possamos experimentar o sentimento de se pertencer a um grupo portador de histórias e manifestações culturais compartilhadas, ao mesmo tempo em que nos tornamos aptos a expressar nossa individualidade por meio de discursos e ações reveladores de uma maneira muito particular de relacionamento com o espaço, o acervo e os serviços disponibilizados por estas instituições, tal qual com os diferentes indivíduos com quem, a partir delas, estabelecemos algum tipo de contato.

Sendo assim, é esse potencial congregador e, ao mesmo tempo, individualizante que confere às bibliotecas públicas a possibilidade de participarem ativamente dos processos que amparam a formulação coletiva e intersubjetiva de certos discursos identitários. Enquanto espaço público que tem por função preservar a memória, promover a leitura, 
fomentar as atividades educativas e informacionais, bem como propiciar experiências de sociabilidade enraizadas em torno dos livros, da informação, do lazer e do conhecimento, elas congregam e alimentam um conjunto de referências práticas, simbólicas e afetivas que permitem a um usuário singular, tanto quanto a uma sociedade inteira traçar uma imagem ou constituir um discurso, uma representação definidora de si mesmos.

Afirmativa endossada pelos depoentes aqui entrevistados, em cujos testemunhos se torna possível visualizar claramente que a Biblioteca Pública Estadual Luiz de Bessa ganha contornos bem demarcados em suas memórias e histórias de vida. Para eles, ela é, a um só tempo, um dos lugares onde a formação pessoal e intersubjetiva de ambos se mostrou potencializada. Um lugar onde a socialização e a relação com o outro, outras pessoas, outros pontos de ancoragem simbólica e afetiva, possibilitou a definição de novos rumos para suas vivências pessoais. Em síntese, um lugar onde as ações e experiências ali concretizadas passaram a refletir diretamente na maneira como cada um desses dois sujeitos se tornaram capazes de definir e expressar, prática e discursivamente, uma imagem de si e do mundo que os cercam. Situação semelhante àquela relatada pela interlocutora de Michàle Petit. Equivalência que salta aos nossos olhos e nos ajuda a melhor entender porque aquela senhora fez questão de dizer que vai à biblioteca, a uma biblioteca pública, para poder existir, assim como o conjunto de razões que leva José F. a afirmar, em certo momento de seu depoimento, que a Biblioteca Pública Estadual Luiz de Bessa transformou-se, para ele, em um espaço que "Ihe preenche todo igualzinho". (JOSÉ, F., 2013, p.18).

\section{Referências}

ALBERTI, Verena. Ouvir contar: textos em história oral. Rio de Janeiro: FGV, 2004.

ARENDT, Hannah. A condição humana. 5. ed. Rio de Janeiro: Forense Universitária, 1991.

BARATIN, Marc; JACOB, Christian (Orgs.). O poder das bibliotecas: a memória dos livros no ocidente. Rio de Janeiro: UFRJ, 2000.

BAUMAN, Zygmunt. Identidade: entrevista a Benedetto Vecchi. Rio de Janeiro: Jorge Zahar, 2005.

BOSI, Ecléa. Entrevista. Dispositiva, Belo Horizonte, v.1, n.2, nov.2012/abr., 2013, p.196-199. Disponível em: http://periodicos.pucminas.br/index.php/dispositiva/article/view/4301/44

54. Acessado em: 09/02/2014.

BOSI, Ecléa. Memória e sociedade: lembrança de velhos. 11 ed. São Paulo: Companhia das Letras, 2004.

BOSI, Ecléa. O tempo vivo da memória: ensaios de psicologia social. 2 ed. São Paulo: Ateliê, 2003. 
CESARINO, Maria Augusta da Nóbrega (Org.). Biblioteca pública estadual Luiz de Bessa: 50 anos de cultura. Belo Horizonte: Secretaria de Estado de Cultura de Belo Horizonte : Superintendência de bibliotecas públicas, 2006.

COHN, Gabriel. Simmel e a depuração das formas. In: Crítica e resignação: Max Weber e a teoria social. 2. ed. São Paulo: Martins Fontes, 2003, p.51-74. (Tópicos).

DOISE, W. Les représentations sociales: définition d'un concept. Connexions, n.45, p.245-253, 1985.

FRANÇA, Vera R. Sociabilidade. Belo Horizonte: FAFICH-UFMG, 15/03/2012. Nota de aula.

FRANÇA, Vera R. Veiga. Discurso de identidade, discurso de alteridade: a fala do outro. In: GUIMARÃES, César [et al]. Imagens do Brasil: modos de ver, modos de conviver. Belo Horizonte: Autêntica, 2002, p.27-43.

FRANÇA, Vera R. Veiga. Sociabilidade: implicações do conceito no estudo da comunicação. In: BRAGA, José Luiz; FAUSTO NETO, Antônio; PORTO, Sérgio D. (Orgs.). A encenação dos sentidos: mídia, cultura e política. Rio de Janeio: Diadorim, 1995, p.55-65.

FROCHTENGARTEN, Fernando. Memórias de vida, memórias de guerra: um estudo psicossocial sobre o desenraizamento. São Paulo: Perspectiva : FAPESP, 2005. (Estudos ; 222).

GAGNEBIN, Jeanne-Marie. "Le printemps adorable a perdu son odeur". Alea, v.9, n.1, jan./jun., 2007, p.64-74.

HALBWACHS, Maurice. A memória coletiva. São Paulo: Centauro, 2006.

HALBWACHS, Maurice. Les cadres sociaux de la memóire. Paris: Presse Universitaires de France, 1952.

HALL, Stuart. A centralidade da cultura: notas sobre as revoluções culturais no nosso tempo. Educação \& Realidade, Rio Grande do Sul, v.22, n.2, jul./dez., 1997, p.15-46.

HALL, Stuart. A diversidade cultural na pós-modernidade. 5 ed. Rio de Janeiro: DP\&A, 2001.

HALL, Stuart. Da diáspora: identidades e mediações culturais. Belo Horizonte: UFMG ; Brasília: Representação da UNESCO no Brasil, 2003.

HALL, Stuart. Quem precisa da identidade? In: SILVA, Tomaz Tadeu da (Org.). Identidade e diferença: a perspectiva dos Estudos Culturais. 8. ed. Petrópolis: Vozes, 2008, p.103-133.

HANKE, Michael. A noção de sociabilidade: implicaçõs nos estudos da comunicação. In: ASSOCIAÇÃO NACIONAL DOS PROGRAMAS DE PÓSGRADUAÇÃO EM COMUNICAÇÃO, 11., 2002, Rio de Janeiro. Anais da XI COMPÓS. Rio de Janeiro, 2002, p.01-11. Disponível em: http://www.compos.org.br/data/biblioteca 744.pdf, Acessado em: 06/03/2012. 
JARAMILLO, Orlanda. La biblioteca pública, un lugar para la formación ciudadana: referentes metodológicos del proceso de investigación. Rev. Interam. Bibliot. Medellín, v.33, n.2, jul./dec., 2010, p.287-313.

JARAMILLO, Orlanda; MONTOYA RÍOS, Mónica. Revisión conceptual de la biblioteca pública. Rev. Interam. Bibliot. Medelin, v.23, n.1-2, enero/diciembre, 2000, p.13-56.

JODELET, Denise (Org.). As representações sociais. Rio de Janeiro: UERJ, 2001.

JODELET, Denise. Formes et figures de I'altérité. In: SANCHEZ-MAZAS, Margarita; LICATA, Laurent. L'autre: regards psychosociaux. Grenoble: Les Presses de I'Université de Grenoble, 2005, p.23-47.

JODELET, Denise. Les représentations sociales dans le chanp de la culture. Social Science Information, Londres, 2002, n.41(1), p.111-133.

JODELET, Denise. Place de l'expérience vécue dans le processus de formation des représentations sociales. In: HASS, Valérie. Les savoirs du quotidien: transmissions, apropriations, représentations. Rennes: Presses universitaires de Rennes, 2006, p.235-255.

JOVCHELOVITCH, Sandra. Vivendo a vida com os outros: intersubjetividade, espaço público e representações sociais. In: GUARESCHI, Pedrinho; JOVCHELOVITCH, Sandra (Orgs.). Textos em representações sociais. 9 ed. Petrópolis: Vozes, 2007, p.63-85.

KOONTZ, Christie; GUBBIN, Barbara (Orgs.). Diretrizes da IFLA para bibliotecas públicas. Brasília: Briquet de Lemos / Livros, 2012.

MEIRY, José Carlos Sebe Bon; HOLANDA, Fabíola. História oral: como fazer, como pensar. São Paulo: Contexto, 2007.

MENESES TELLO, Felipe. Bibliotecas y sociedad: reflexiones desde uma perspectiva sociológica. Rev. Interam. Bibliot. Medelin, v.28, n.2, jul./dic., 2005, p.117-133.

MOSCOVICI, Serge. Representações sociais: investigações em psicologia social. 4 ed. Petrópolis: Vozes, 2003.

MÜLLER, Suzana P. M. Biblioteca e sociedade: evolução da interpretação das funções e papéis da biblioteca. R. Esc. Bibliotecon. UFMG. Belo Horizonte, 13(1): 7-54, mar. 1984.

PETIT, Michèle. A arte de ler: ou como resistir à adversidade. São Paulo: Ed. 34, 2009.

PETIT, Michèle. Leituras: do espaço íntimo ao espaço público. São Paulo: Editora 34, 2013.

PETIT, Michèle. Les territoires invisibles et vitaux de la lecture. Strates, n.14, 2008, p.01-11.

SILVA, Tomaz Tadeu da (Org.). Identidade e diferença: a perspectiva dos Estudos Culturais. 8. ed. Petrópolis: Vozes, 2008. 
SILVEIRA, Fabrício José Nascimento da. Biblioteca pública, identidade e enraizamento: elaborações intersubjetivas ancoradas em torno da Luiz de Bessa. 2014. 252f. Tese (Doutorado em Ciência da Informação) - Escola de Ciência da Informação da Universidade Federal de Minas Gerais, Belo Horizonte, 2014.

SILVEIRA, Fabrício José Nascimento da. Biblioteca, memória e discursos identitários: uma leitura sócio-histórica dos depoimentos colhidos pelo Projeto Memória Oral da Biblioteca Mário de Andrade (BMA). Tendências da pesquisa brasileira em Ciência da Informação, v.5, n.1, 2012, 23p. Disponível

em: http://inseer.ibict.br/ancib/index.php/tpbci/article/view/76/118. Acessado em: 06/09/2013.

SIMMEL, Georg. Questões fundamentais da sociologia. Rio de Janeiro: Jorge Zahar, 2006. (Nova biblioteca de ciências sociais).

SIMÕES, Paula Guimarães. O acontecimento Ronaldo: a imagem pública de uma celebridade no contexto social contemporâneo. 2012. 283f. Tese (Doutorado em Comunicação Social) - Faculdade de Filosofia e Ciências Humanas da Universidade Federal de Minas Gerais, Belo Horizonte, 2012.

SOUZA, Jessé; ÖELSE, Berthold (Orgs.). Simmel e a modernidade. 2. ed. Brasília: UNB, 2005.

WAIZBORT, Leopoldo. As aventuras de Georg Simmel. São Paulo: USP, Curso de pós-graduação em sociologia : Ed.34, 2000.

WAIZBORT, Leopoldo. Elias e Simmel. In: WAIZBORT, Leopoldo (Org.). Dossiê Norbert Elias. 2. ed. São Paulo: Edusp, 2001, p.89-111.

WEIL, Simone. A condição operária e outros estudos sobre a opressão. Seleção e apresentação de Ecléa Bosi. 2. ed. Rio de Janeiro: Paz e Terra, 1996.

WEIL, Simone. O enraizamento. Bauru: EDUSC, 2001.

\section{Fontes}

José F. Belo Horizonte, Brasil, 22 jul. 2013, áudio. Entrevista concedida a Fabrício José Nascimento da Silveira para a realização da tese de doutorado intitulada Biblioteca pública, identidade e enraizamento: elaborações intersubjetivas ancoradas em torno da Luiz de Bessa. 21 páginas de transcrição.

Luiz Q. Belo Horizonte, Brasil, 10 jun. 2013, áudio. Entrevista concedida a Fabrício José Nascimento da Silveira para a realização da tese de doutorado intitulada Biblioteca pública, identidade e enraizamento: elaborações intersubjetivas ancoradas em torno da Luiz de Bessa. 18 páginas de transcrição. 